\title{
Schleiermacher lee a Platón. Observaciones sobre los Principios de una crítica a las éticas anteriores (1803) y su relación con la Introducción a las obras de Platón (1804)
}

\author{
Schleiermacher reads Plato. Remarks on the Outlines \\ of a critique of previous ethical theories (1803) \\ and its relation to the Introduction to Plato's work (1804)
}

\author{
ANDRÉ LAKS \\ Université de Paris-Sorbonne \\ Universidad Panamericana
}

\begin{abstract}
RESUMEN: Si bien la importancia que tiene Platón para Schleiermacher no es un secreto para nadie, ésta casi siempre se refiere de manera exclusiva a la traducción de los diálogos y a la famosa Introducción que le antecede. Ahora bien, dicha Introducción únicamente versa sobre la forma de los diálogos platónicos, y por muy importante que dicha forma sea, no representa sino un aspecto de la relación que une a Schleiermacher con Platón. Tratándose del contenido, es conveniente llevar a cabo de manera paralela la lectura de la Introducción (1804) y la de los Principios de una crítica a las éticas anteriores (1803). En esta última obra, en efecto, Platón desempeña un papel central como pensador sistemático (al lado de Spinoza con quien se halla asociado con frecuencia) y el único entre los antiguos que tiene una visión correcta de la teoría ética. Una de las interrogantes que se plantea, entonces, es cómo articular el elogio constante que Schleiermacher hace a la ética platónica en el tratado de 1803, con las críticas que también le hará a Platón en obras ulteriores, en particular en su introducción a la traducción de la República (1828).
\end{abstract}

ABSTRACT: Plato's central importance for Schleiermacher is well known, but more often it is linked to Schleiermacher's translation of Plato's work into German and the famous Introduction that precedes it. However, the Introduction focuses only on the dialogical form, representing only one side of Schleiermacher's relationship with Plato. To get a sense about how Schleiermacher's interest in the form of the dialogues is related to the content of Plato's philosophy, one should read the Introduction (1804) along with the quasi-contemporaneous Outlines of a critique of previous ethical theories (1803). In the latter, Plato is depicted as a systematic thinker frequently associated to Spinoza, both on the right track as far as ethical theory is concerned. An interesting question arises when it comes to reconciling Schleiermacher's emphatic praise of Plato in this work and the severe criticisms that he later on raises against Plato's ethics in his specific introduction to the translation of Plato's Republic (1828).

Palabras clave: Schleiermacher, Platón, Spinoza, ética, sistema, diálogo.

KEY words: Schleiermacher, Plato, Spinoza, ethical theory, system, dialogue.

RECIBIDO: 15 de enero de 2015 - ACEPTADO: 22 de abril de 2015 



\begin{abstract}
ANDRÉ LAKS
Université de Paris-Sorbonne

Universidad Panamericana

\section{Schleiermacher lee a Platón.}

Observaciones sobre los Principios de una crítica a las éticas anteriores $(\mathbf{1 8 0 3})$ y su relación con la Introducción a las obras de Platón (1804)*
\end{abstract}

Por crucial que sea la importancia que se le ha dado a Platón entre los pensadores postkantianos, en el contexto del programa de la superación de Kant, es Schleiermacher ${ }^{1}$ quien le otorga a Platón el lugar más importante, más constante y también más original. Cuando se trata de la obra filosófica y teológica de Schleiermacher, se habla a menudo de su "platonismo". El sentido del término requiere cierta precisión, ${ }^{2}$ pero es innegable que la referencia es siempre positiva cuando se trata de los primeros principios de la filosofía, y de manera general es frecuente y decisiva, bien sea en los Discursos sobre la religión, en las diferentes versiones de su Dialéctica, de su Ética, de su Estética, o también en varias comunicaciones pronunciadas en

Agradezco a Liliana Carolina Sánchez Castro (Fundación Universitaria Autónoma de Colombia) por su traducción del original francés y a Nicole Ooms (Centro Peninsular en Humanidades y Ciencias Sociales de la UNAM) por la revisión final del texto.

1 Sobre el lugar de Platón en los pensadores postkantianos, véase especialmente Vieillard Baron 1979 y Asmuth 2006.

2 Sobre el "platonismo" de Schleiermacher, véase Gadamer 1979; Vorsmann 1968; Moretto 1984; Neschke-Hentschke 1990; Rohls 2000; Brino 2007a y 2007 b. 
la Academia de Berlín. Además, esta presencia filosófica de Platón en Schleiermacher se acompaña - y esto lo hace único entre sus contemporáneos - de un trabajo exegético e histórico de toda una vida, por un lado, con la primera traducción casi completa al alemán de los Diálogos y la serie de introducciones que los acompañan (un trabajo que se extendió de 1804 a 1828) y, por el otro, con diversos artículos y cursos consagrados a Sócrates y Platón. ${ }^{3}$ La traducción ejerció una influencia no solamente científica - y ésta fue considerable-, sino también cultural, incluso más allá de las fronteras alemanas. ${ }^{4}$ La Introducción general a la traducción de Platón, que data de 1804, constituye una etapa crucial en los estudios platónicos modernos, hasta el punto de haberse convertido en el blanco principal de los defensores de la llamada lectura "esotérica" de Platón, en virtud de la cual la interpretación de los diálogos encontraría su fundamento, no en los diálogos mismos - como lo piensa Schleiermacher-, sino en la enseñanza oral dada por Platón al círculo de sus discípulos más próximos y mejor preparados (para los esotéricos, los diálogos poseen un objetivo esencialmente propedéutico) ${ }^{5}$

La abundancia y diversidad de los materiales relativos a Platón en la obra de Schleiermacher, junto con la originalidad de la constelación que dibujan, hacen que sea difícil evitar preguntarse por la relación existente entre el trabajo exegético que Schleiermacher llevó a cabo sobre el corpus platónico y su propia reflexión filosófica. Esto mismo vale tanto por sus contenidos, como a nivel metodológico por el

3 Las referencias a la Introducción general a la traducción de Platón corresponden a la paginación de la segunda edición (B) de PW, I/1 (citada como PW), mientras que las de las otras introducciones son a la paginación de la segunda edición de PW, I/2. El conjunto de las introducciones de Schleiermacher a Platón están reunidas, con indicación de la paginación original, en el volumen Über die Philosophie Platons, editado en 1996 por P. M. Steiner, quien incluye muchos otros documentos relativos a Platón (en los que se encuentran extractos de los cursos de Schleiermacher).

4 Moretto 1984 : 234-236, sobre Leopardi, quien ya en 1825 expresa su deseo de tener un equivalente italiano.

5 La tesis del esoterismo platónico, inicialmente desarrollada por la llamada escuela de Tübingen, dio lugar a trabajos importantes. Una muestra representativa de las posturas defendidas fue recogida por Brisson 1998. Respecto de la crítica de Schleiermacher, véase por ejemplo Szlezák 1997 (así como su contribución en la selección antes citada). Para una lectura crítica de esta postura de Schleiermacher, véase Scholtz 1995b y Thouard 1998. 
acto interpretativo mismo, es decir, la hermenéutica. ${ }^{6}$ Esta relación es compleja porque implica que los dos aspectos cuidadosamente distinguidos por Schleiermacher, el de la forma y el del contenido, estarían correctamente articulados. Ahora bien, ocurre que dos obras más o menos contemporáneas, los Grundlinien einer Kritik der bisherigen Sittenlehre (Principios de una crítica a las éticas anteriores) de 1803, donde Platón ocupa un lugar sobresaliente, y la Introducción general a la traducción de las obras de Platón de 1804, están consagradas a estos dos niveles, respectivamente. Nada parecería más natural, entonces, que leer estos dos textos de manera conjunta. Como esto, hasta donde tengo conocimiento, no se ha llegado a hacer jamás, me propongo presentar en lo que sigue los contornos de una lectura de este tipo.?

La Introducción general a los diálogos de Platón ocupa aproximadamente cincuenta páginas y tiene como particularidad que no dice nada, o casi nada, sobre la filosofía platónica propiamente dicha, es decir, sobre su doctrina: "Es intencionalmente que no se dirá nada por ahora, sobre la filosofía misma de Platón, aun cuando fuera fácil hacerlo". ${ }^{8}$ Apenas advertimos en la Introducción que Platón es "en cierto sentido" el primero en haber dividido la filosofía en disciplinas distintas y en haber pensado la unidad última de las mismas ${ }^{9}$ - se debe subrayar que esto corresponde al proyecto general de Schleiermacher en cuanto a su propio sistema filosófico- - Lo que la Introducción se propone explicar no es el sistema de Platón, sino las características formales de su obra. Es significativo, desde este punto de vista, que Schleiermacher presente su Introducción como si estuviera añadiendo un "complemento" a la presentación "analítica" que Tennemann, una docena de años antes, había proporcionado de la doctrina de Platón en su Sistema de la filosofía platónica.$^{10}$ Las ca-

Este punto fue desarrollado por Neschke-Hentschke 1990.

Para una primera tentativa, véase Laks 1990.

Introducción, PW I/1, p. 5.

9 Introducción, p. 9. "En un cierto sentido", pues Sócrates tiene también pretensiones de ese tipo (véase la exposición académica de 1814/1815, "Über den Werth des Sokrates als Philosophen").

10 Tennemann 1792/1795. Schleiermacher compara el trabajo de Tennemann (cuyo nombre no cita) con el del anatomista que diseca (Introducción, p. 17). El "complemento" -el término ya ha sido empleado (p. 7) - consistirá en reconstituir la articulación 
racterísticas formales en cuestión son dos y conviene distinguirlas: por un lado, la forma dialógica de cada uno de los diálogos; por el otro, la organización de conjunto de los diferentes diálogos dentro de la serie que se supone que forman.

Según Schleiermacher, Platón mismo esbozó, en un pasaje del Fedro que se volvió célebre por aquel tiempo - se trata de la discusión sobre el valor de la escritura (275c-277a) - , una concepción "de sus escritos y de su propósito" que permite justificar el recurrir a la forma dialógica. ${ }^{11}$ El problema del que parte Schleiermacher es el de la comunicación del pensamiento: "hermenéutica" en el sentido original del término. La obra escrita se enfrenta siempre al problema de que nunca podemos saber con certeza "si el alma del lector reproduce las ideas por una actividad propia (Selbsttätigkeit) y si, consecuentemente, se las apropia en realidad, o si la comprensión aparente de las palabras y de las letras no produce en dicha alma otra cosa que la vana ilusión de saber aquello que ella aún no sabía" ${ }^{12} \mathrm{La}$ enseñanza oral tiene cierta ventaja sobre la enseñanza escrita porque "aquel que enseña [...] puede a cada instante saber lo que [el discípulo] ha comprendido y lo que no, y asimismo acudir en ayuda de la actividad de su inteligencia, en caso de fracaso". ${ }^{13}$ Dicha enseñanza tomará entonces, naturalmente, la forma de un diálogo. De ahí que la selección del diálogo para la enseñanza escrita no sea más que la tentativa "de producir una enseñanza escrita lo más parecida posible a aquella otra enseñanza que es mejor". ${ }^{14}$

natural de los componentes (las "opiniones particulares") en un solo cuerpo, al que Schleiermacher nombra, irónicamente, "su pobre entrelazamiento" (ibid.). Sobre el trabajo de Tennemann, véase Szlezák 1997 (quien estima que el enfoque de Tennemann es superior al de Schleiermacher desde una perspectiva "esotérica").

11 Introducción, p. 17.

12 Introducción, p. 17; cf. p. 21. Más adelante, Schleiermacher recuerda que "el objetivo principal de Platón [...] es provocar [en el lector] la producción de sus propias ideas; toda nuestra clasificación reposa sobre el reconocimiento de este hecho". La idea de Selbsttätigkeit es una herencia de Fichte.

13 Introducción, p. 18.

14 Introducción, p. 19. La presencia de una reflexión sobre la comunicación de la filosofía le proporciona a Schleiermacher una justificación de la vieja idea según la cual el Fedro es el más antiguo de los diálogos de Platón en razón de su carácter juvenil (cf. Diógenes Laercio, III, 38), cosa que ya nadie admite. 
Pero la especificidad de los diálogos platónicos no se agota en la forma dialógica. Su "propósito" propiamente dicho, en oposición a las necesidades que impone la estructura misma de la comunicación (expuesta como está a malentendidos y a la incomprensión), se hará notar sobre todo en el principio de la sucesión de los diá$\operatorname{logos}{ }^{15}$ que la Introducción pretende mostrar. La operación supone una clasificación de los diálogos transmitidos, la cual tiene antecedentes antiguos que Schleiermacher conoce y utiliza para volver a elaborarla. ${ }^{16}$ Después de haber separado las obras espurias de las auténticas y, en el seno de ellas, los diálogos llamados "de circunstancia" de las obras principales, estos últimos se organizan en tres grupos. ${ }^{17}$ Schleiermacher supone que este orden corresponde a los imperativos de un recorrido "didáctico". La idea es antigua, pero la originalidad de Schleiermacher - que es también fuente de cierta dificultad - consiste en plantear que este orden obedece también al despliegue del propio pensamiento de Platón, que parte de una idea seminal de la unidad del sistema de las ciencias y de la infinitud del primer principio, hasta la exposición de las dos ciencias reales: la física y la ética. ${ }^{18}$ Así, a los diálogos "introductorios" y, desde un punto de vista pedagógico, puramente catárticos, siguen los diálogos intermedios donde el sistema se esboza, pero sólo de manera preparatoria o indirecta. Únicamente encontrará su punto de culminación en dos diálogos donde el sistema de las ciencias reales se presenta de manera directa: es decir el Timeo para la física y la República para la ética. ${ }^{19}$

15 Schleiermacher habla a propósito de ello de "forma auténticamente platónica", Introducción, pp. 29-39.

16 Sobre las clasificaciones antiguas, cf. Diógenes Laercio III, 49-50 y 56-62.

17 Las obras reconocidas como principales en la Introducción general son las siguientes: Fedro, Protágoras, Parménides, Teeteto, Sofista, Político, Fedón, Filebo, República, Timeo y Critias (p. 35). Sobre el estatus del Banquete, véase Arndt 2002.

18 Esta doble perspectiva define lo que Schleiermacher llama "la serie natural de los escritos [de Platón]”, pp. 26 s. Schleiermacher admite que puede haber un desfase, en ciertos casos, entre el proyecto pedagógico y el recorrido sistemático.

19 Introducción, pp. 45-51. A diferencia de los neoplatónicos, el Parménides no forma parte de la cumbre del sistema platónico, sino que es un diálogo puramente preparatorio. He aquí, a manera de ejemplo, lo que Schleiermacher dice de la $R e$ pública: "la República, sin lugar a dudas el primero de los diálogos de exposición 
Las indicaciones del Fedro no son suficientes para dar cuenta de esta construcción. Ésta es la razón por la cual Schleiermacher considera que Platón, en el Fedro, no hizo más que esbozar la teoría de sus propios escritos sin llevarla a término..$^{20}$ De hecho, Platón no escribe solamente para aquellos que, sabiendo ya, buscan recordar (ésta es la función limitada que el Fedro le asigna al escrito filosófico), sino que intenta también, sobre todo, "llevar a saber al lector que no sabe todavía". ${ }^{21}$ No es que él mismo "sepa ya", 22 dado que justamente Schleiermacher supone que la progresión de los diálogos en dirección de la fundamentación del sistema corresponde al desarrollo del propio pensamiento de Platón a partir de su intuición original. La "serie natural" de los diálogos responde a esta doble perspectiva, ya que ella va "del primer despertar de ideas originales y rectoras hasta una presentación, por inacabada que sea, de las ciencias particulares". Si la construcción de la "sucesión natural" de los diálogos reposa enteramente sobre el concepto de "actividad propia", esto quiere decir que el lector, que se encuentra completamente asociado a la producción aunque esté sólo en vías de constitución, también emprende libremente el camino que, no menos libremente, el autor mismo recorre.

propiamente dicho, presupone todos los que no pertenecen a esta categoría. Este suntuoso edificio contiene, por así decirlo, ancladas en su pavimento las llaves de todas estas bóvedas majestuosas sobre las que reposa y, antes de adentrarse en esta construcción, si se las considera en sí mismas, limitando a éstas el horizonte de nuestra mirada, tendremos la tentación de declararlas inútiles y casi inacabadas, porque no se tiene la menor idea de su destino" (Introducción general, pp. 46 s.). En la introducción al Cármides, Schleiermacher dice que se podrían considerar "las pequeñas exposiciones del Laques y del Cármides como ejercicios preparatorios y una introducción a los desarrollos más amplios de la República a propósito de la justicia" (Introducción al Cármides, p. 5). El otro diálogo principal referido es el Protágoras (por la doctrina de la unidad de la virtud que es esbozada allí). En la p. 6 de la Introducción general, Schleiermacher menciona también el Lisis.

20 Schleiermacher no sostiene allí más que la composición secuencial de los diálogos, esta "forma auténticamente platónica [...] no es otra cosa que la aplicación directa de estas ideas sobre el método que hemos desarrollado a partir del primer principio de Platón sobre la manera en que se lleva a cabo la escritura", Introducción, p. 40.

21 Introducción, p. 19.

22 Los "esotéricos" parten, por el contrario, de la idea de que Platón estuvo muy temprano en plena posesión de su doctrina de los principios, a partir de la República en todo caso, y que esto pudo haber sido el caso inclusive antes de emprender la escritura de sus primeros diálogos (sobre este debate, véase Szlezák 1997). 
En la medida en que quiere ser una introducción no al sistema, sino al modo de presentación del mismo, se entiende que la Introducción no habla del sistema mismo sino de manera vaga o general. ${ }^{23}$ Se puede aprender un poco más sobre el aspecto doctrinal en las introducciones específicas a cada diálogo y, sin lugar a dudas, es primero en esas introducciones que piensa Schleiermacher cuando escribe que "es a propósito que no se dirá nada por el momento sobre la filosofía del mismo Platón". ${ }^{24}$ Pero lo que se saca de allí sobre la interpretación puramente schleiermacheriana es también limitado: por una parte, estas introducciones específicas inicialmente están consagradas a una justificación detallada del lugar del diálogo, en el marco de la serie que no había sido proporcionada en la Introducción general; por otra parte, la interpretación sistemática se encuentra desarrollada solamente en tanto que ella le es útil, localmente, al propósito exegético.

Éste no es el lugar para examinar las introducciones una por una. En todo caso, volveré sobre la República después. Y a falta de una introducción al Timeo que, por razones que serán evidentes un poco más adelante, hubiera sido, sin lugar a dudas, una de las introducciones más instructivas, pero que Schleiermacher no tuvo tiempo de redactar (tampoco tradujo el diálogo), algunas indicaciones sobre la introducción al Sofista (1808) nos serán útiles sin embargo.

Schleiermacher considera que el sistema platónico constituye el primer ejemplo verdaderamente articulado de una filosofía de la identidad (identidad del ser y del pensamiento; identidad de los opuestos en la unidad suprema del ser y del pensamiento). ${ }^{25}$ El sistema de Platón presenta, a sus ojos, una ventaja sobre un pensamiento como el de Schelling que se atiene a la naturaleza: a saber que dicho sistema expone las dos primeras ciencias reales - la física y la ética- en

23 Las últimas páginas de la Introducción general no tratan la filosofía expuesta en los diálogos sistemáticos sino en la medida en que es necesaria para la distinción entre este último grupo de diálogos y los diálogos introductorios e intermedios.

${ }^{24}$ Cf. supra, p. 41.

25 Pero no es el primero: Heráclito es, de hecho, un pensador de la unidad de opuestos, y es esta unidad en el seno de los principios la que se halla en la médula del gran estudio de Schleiermacher sobre Heráclito, también de 1808. El paralelo merece ser profundizado. Algunas indicaciones al respecto en Laks 2011. 
las que la identidad originaria se divide. Éstas son las dos ciencias de las que se ocupan el Timeo y la República. Por otro lado, es en el Sofista - del que subraya que es un diálogo sobre el ser, lo cual significa que a su modo de ver, ni "el sofista" ni tampoco el "no-ser" constituyen el centro de dicho diálogo,$-{ }^{26}$ donde Schleiermacher ve esencialmente perfilarse una cierta filosofía de la identidad. ${ }^{27}$ Es la razón por la cual Schleiermacher, en la introducción a este diálogo, termina llamándolo el "santuario" ('das innerste Heiligtum') ${ }^{28}$ de la filosofía platónica, el analogon de su propia Dialéctica.

Schleiermacher retiene del Sofista esencialmente dos cosas: en primer lugar, una concepción del ser como "ser total", a la vez que "uno y múltiple, en movimiento y en reposo" (249d), unidad suprema del ser en el seno del cual los opuestos coinciden y que, contrariamente a la suposición común de los Amigos de la Tierra y de los Amigos de las Formas, está dotado de "movimiento, de vida, de alma y de razón” (248e). Aquí vemos claramente que se dibuja, según la expresión de G. Scholtz, "una suerte de teología especulativa" con la cual Schleiermacher sin lugar a dudas se identifica, como lo muestran algunos pasajes de la Dialéctica.$^{29}$ Por otra parte, Schleiermacher reconoce también, en el célebre pasaje sobre los cinco géneros supremos y su "comunidad" (koinônía), ${ }^{30}$ una teoría sistemática de los diferentes tipos de conceptos y de su alcance ontológico-epistemológico que hace también eco a su Dialéctica. Según la presentación sintética ofrecida en los cursos sobre la historia de la filosofía - que permiten precisar la interpretación-, el concepto de "ser" remite al ser total, es decir, a la unidad suprema de los opuestos, ${ }^{31}$ los conceptos de Lo mismo y de Lo otro definen la esfera de términos "sujetos" ("Subjekt-

26 Cf. Introducción al Sofista, p. 136. El Sofista puede en cierta manera ser completado por el Banquete que, según Schleiermacher, sustituye al Filósofo en la trilogía inacabada de Sofista, Político, Filósofo (sobre esta cuestión, véase Arndt 2002).

27 'Se perfila', porque en la reconstrucción de Schleiermacher, no pertenece al grupo de los diálogos de exposición (aquellos que presentan directamente la doctrina), sino a los diálogos intermedios, llamados "indirectos", que desde una perspectiva didáctica solamente juegan un papel preparatorio.

28 Cf. Introducción al Sofista, p. 136 (cf. Scholtz 1995b: 849 ss.)

29 Scholtz 1995 b, nota 9.

30 Cf. especialmente 253 c y $254 \mathrm{~b}$.

31 GPh, p. 100. 
begriffe"), obtenidos y clasificados de manera deductiva y científica por medio de la división (dieresis); los conceptos de Movimiento y Reposo, finalmente, corresponden a la esfera de los "conceptos empíricos" provenientes de la experiencia (Erfahrungsbegriffe) y que son la fuente del juicio. ${ }^{32}$ La lectura schleiermacheriana del Sofista, que, por su doble orientación ontológica y epistemológica (conceptual), exhibe (aun cuando sea de manera indirecta) la identidad del pensamiento y del ser, desemboca así en una interpretación que ve en las Ideas platónicas no solamente conceptos generales, en tanto géneros y especies, sino también fuerzas que operan en el mundo del devenir - los dos aspectos complementarios están reflejados en la doble designación como eidos e idea.$^{33}$ Las ideas platónicas, según Schleiermacher, al ser conceptos reales, es decir que actúan en el mundo - tanto en el ámbito físico como en el ámbito moral — son la expresión misma de la potencia divina. ${ }^{34}$

Ahora bien, estas indicaciones generales permiten entender mejor el tratamiento a Platón en los Grundlinien, que no son solamente la más antigua sino también la más completa de nuestras fuentes, tratándose de la interpretación sistemática que Schleiermacher dio de Platón. De la Introducción se deprende que, si la serie de diálogos, fundada ésta sobre el concepto de actividad propia, mantiene con el sistema una relación que no es de pura exterioridad, dado que dicha serie sigue su desarrollo, ${ }^{35}$ el diálogo en tanto tal permanece contingente en relación con el sistema, en la medida en que aquél surge de una teoría de la comunicación de un sistema que preexiste de derecho. Esta configuración, esencial para comprender los diferentes as-

32 GPh, p. 101.

33 Schleiermacher en ocasiones llega a sugerir que existen tanto las ideas como las fuerzas individuales, GPh, p. 102. Nuestro autor llega así a una concepción de las Ideas totalmente opuesta a la de Aristóteles, quien le reprocha a las Ideas platónicas el no poseer poder causal alguno (cf. Metafísica, A9, 991 a 9-11).

34 Schleiermacher aquí es dependiente de la interpretación que el platonismo medio hace de la teoría de las Ideas, la cual declara que estas últimas son las Ideas de Dios (véase Neschke-Hentschke 1990:142 s.). Sobre las Ideas como pensamientos de Dios, cf. Grundlinien, p. 35 (citado infra,p. 36); esta fórmula evidentemente jugó un papel importante durante la larga historia de la cristianización de Platón, de la cual Schleiermacher es heredero.

35 Cf. supra, n. 18. 
pectos de la relación de Schleiermacher con Platón, se ve confirmada por los Grundlinien, que, por su parte, se interesan en la doctrina de Platón, independientemente de la pregunta por su forma de comunicación. ${ }^{36}$ La mejor prueba de ello es que esta última cuestión es tratada en el marco de un Apéndice (Anhang) consagrado a las diferentes formas de exposición de las doctrinas morales. El carácter distintivo del modo de escritura platónica será el de provocar un "choque eléctrico", de acuerdo con una fórmula interesante que expresa bien el efecto que, según Schleiermacher, resulta del método socrático, aun cuando dicha fórmula no se mencione en la introducción de $1804 .{ }^{37}$

Los Grundlinien se dividen en tres libros: ${ }^{38} \mathrm{I}$. "Crítica del principio supremo de moralidad" (pp. 19-120); II. "Crítica de los principios éticos" (pp. 121-246); III. "Crítica del sistema ético" (pp. 247-345). ${ }^{39}$

La secuencia Principio-Conceptos-Sistema corresponde a una determinación progresiva del campo de la ética, desde los términos más generales hasta los más específicos. (1) El principio ético tiene como función procurar el fundamento de un conjunto sistemático de proposiciones éticas derivadas de manera deductiva. Debe abarcar los tres aspectos esenciales que supone toda acción ética (en este caso, toda acción buena): a) el poder o la capacidad de actuar bien en general; $b$ ) la regla por seguir; $c$ ) el bien que se contempla o se realiza. (2) A los conceptos éticos que regulan las condiciones de la elección moral, corresponden las tres siguientes ideas: $\left.a^{\prime}\right)$ el ideal del sabio, que no es otra cosa que la encarnación de la capacidad de elegir bien, un ideal que se concreta en una doctrina de la virtud (Tugendlehre); b') el ideal de bien supremo, que se concreta en una doctrina de los bienes (Güterlehre) y trata las diferentes formas que

36 En mi artículo de 1990 sugerí que, sobre este punto, la lectura de Schleiermacher había evolucionado. Mientras que en 1803/1804 la dialéctica platónica es un rasgo esencialmente formal de la obra de Platón, es decir una propiedad de su escritura filosófica, esta misma es presentada más tarde, y de manera notable en la Dialéctica de 1811 , como una dimensión inherente al sistema, del mismo modo en que se presenta en el sistema del mismo Schleiermacher.

37 Kritische Gesamtausgabe I, 4, p. 349.

38 Están precedidos por un Prefacio y una Introducción, y seguidos del Apéndice que ya mencioné.

39 Sobre los Grundlinien, véase Brino 2007a, y sobre el lugar de Platón en particular, Brino 2007b. 
toma la búsqueda del bien supremo en circunstancias definidas; $c^{\prime}$ ) finalmente, la idea de la ley moral, la cual se encarna en la regla que se sigue en cada ocasión, por ejemplo el deber. (3) En cuanto a la sistematicidad de un sistema ético, ésta tiene esencialmente que ver con la completud de dicho sistema: se mide con base en el hecho de que no se descuide ninguna temática de alcance ético. Se mencionarán allí como ejemplos significativos y que juegan un papel en la apreciación de Platón los siguientes aspectos: la relación entre el aspecto universal y el aspecto individual de la acción moral; la toma en consideración del amor y de la amistad en la lista de los elementos que son relevantes en una ética; la parte otorgada al conocimiento en la teoría moral (bajo los aspectos del conocimiento del bien y del mal); la dimensión moral del arte, ${ }^{40}$ así como, last but not least, la cuestión del Estado, que juega un papel particular en la relación de Schleiermacher con Platón, y a la cual volveré más adelante. ${ }^{41}$

Conceptualmente, la búsqueda de Schleiermacher está organizada en función de cuatro pares de criterios cuyo despliegue genera una cartografía exhaustiva de los sistemas éticos. Estos sistemas son:

1) los sistemas de bienestar (Glückseligkeit) o de la perfección (Vollkommenheit);

2) los sistemas de la naturaleza (Natürlichkeit) o de la moralidad (Sittlichkeit);

$40 \quad$ Grundlinien, p. 267, cf. pp. 66; 285, 288, 289.

41 "Weit allen andern voraus ist auch hier wieder Platon, welcher von Freundschaft und Liebe ... so zusammenhängend redte, dass es leicht wäre, aus allem, was zerstreut darüber vorkommt, ... ein Ganzes zu machen. Es darf nun erinnert werden, wie er symbolisierend den Geschlechtstrieb mit dem Bestreben nach gemeinsamer Ideenerzeugung verbindet, und auf die Unvollkommenheit des persönlichen Daseins und seine Unzulänglichkeit zur Hervorbringung eines höchstens Gutes diese Aufgabe gründet" ("Platón es aquí de nuevo un pionero frente a todos los demás (filósofos). Habla con tanta coherencia de la amistad y del amor, que sería fácil hacer una totalidad de todo lo que ocurre disperso al respecto (de la amistad y el amor). Ahora bien, podemos recordar cómo él (Platón) vincula simbólicamente el impulso sexual con el esfuerzo por la producción común de ideas y cómo basa esta tarea en la imperfección de la existencia personal y en su insuficiencia para dar lugar a un bien supremo"), p. 265. Para lo que se refiere al Estado (omitido de manera significativa por Vorsmann (1968) en la enumeración de la p. 36), véase infra, p. 57. 
3) los sistemas de la restricción (beschränkende Ethik) o de la "formación" (bildende Ethik);

4) los sistemas orientados hacia la generalidad (das Ethische als Allgemeines) o hacia el individuo (das Ethische als Individuelles) ${ }^{42}$

La empresa es crítica, en el sentido ordinario del término, y no pretende de ninguna manera proporcionar una exposición positiva. Se trata, antes que nada, de juzgar de la falsedad, o en dado caso, de la corrección de las doctrinas éticas atestiguadas históricamente. Se concluye que, a través del sistema de cuestiones que Schleiemacher formula y del examen de respuestas que proporciona, reproduce o construye, se dibujan los lineamientos de su propia ética, lo más directamente posible, pero también algunas veces de manera explícita. ${ }^{43}$

Tres de los cuatro pares de criterios rectores se constituyen a partir de términos subcontrarios: el principio de una ética auténtica, entonces, tendrá que buscarse en una tercera noción. Así, ni el bienestar ni la perfección pueden pretender el título de principio ético, porque tienen en común el hecho de ser estados pasivos: ${ }^{44} \mathrm{El}$ verdadero principio es aquí la actividad (Tätigkeit). Cuando se trata del segundo par, el principio no será ni la naturaleza ni la moralidad, que se inscriben ambas en una perspectiva dualista; por el contrario, es un monismo que Schleiermacher presupone. ${ }^{45}$ Para el del cuarto par (general vs. individual), finalmente, sólo es aceptable una posición

$421 .=$ pp. $41-51 ; 2 .=$ pp. $51-53 ; 3 .=$ pp. $54-61 ; 4 .=$ pp. 61-69. Véase el sumario en la edición de O. Braun, pp. CIV-CVI.

43 Desde este punto de vista, lo que Schleiermacher escribe en una carta de 1802 dirigida a Eleonore (Aus Schleiermachers Leben. In Briefen, 1, 1860, p. 326) no refleja del todo la realidad: "Denn da ich meine moralischen Grundsätze nicht voranschicke, so kann ich auch die bisherigen Moralen nicht von der Seite angreifen, dass ich sie für unmoralisch halte, sondern nur von der Seiten der wissenschaftlichen Unvollstandigkeit und Schlechtigkeit, wobei also jenes nur sehr seitwärts durchschimmern kann" ("Pues dado que yo no pongo al inicio mis principios morales, tampoco puedo atacar las antiguas 'teorías' morales por considerarlas inmorales, sino más bien por el lado de su falta de completud y su deficiencia científicas, de manera que no se vislumbran sino tangencialmente").

44 La felicidad se define como un "estado del alma" ("Beschaffenheit der Seele", p. 40). Y la perfección, una vez alcanzada, no deja lugar a ninguna acción.

45 Herms 1992, asimila las dos posiciones, por una parte, a un monismo (NatürlichkeitNaturalismo) y, por otra parte, a un dualismo (Sittlichkeit-Moralidad). 
sintética que no sacrifique ni el aspecto general de la ética en beneficio del aspecto individual, ni tampoco el aspecto individual en beneficio del aspecto general. Es solamente en el tercer par que uno de los términos del par original satisface el requisito ético, dado que tampoco existe, a ojos de Schleiermacher, una ética verdadera que no sea "formadora" (bildende). De hecho, entre todos los criterios, es éste al que Schleiermacher otorga la mayor importancia, puesto que "formación" contra "limitación" no es otra cosa que Platón contra Kant.

La crítica se apoya en una división casi doxográfica de las doctrinas anteriores, en función de los criterios mencionados. La organización del tema está lejos de ser absolutamente nítida: las posiciones críticas no se acompañan de ninguna otra referencia sino de la del nombre de su autor, el argumento es a menudo alusivo, los desarrollos densos y su articulación poco visible. ${ }^{46}$ No es, como se ha sugerido, que Schleiermacher quiera ejercer a la manera platónica la Selbsttätigkeit de su lector para dirigirlo hacia el saber, ${ }^{47}$ Schleiermacher explica en su prefacio, por el contrario, que su obra fue escrita para gentes ya informadas (en particular aquellos que tienen en mente la historia de la filosofía de Tenemann). ${ }^{48}$

Schleiermacher distingue sistemáticamente los antiguos de los modernos. Entre estos últimos, son citados sobre todo Spinoza, los ingleses (Shaftesbury, Garve), Kant, Fichte y Schelling; entre los antiguos, se encuentran predominantemente Platón, Aristóteles, los estoicos, Epicuro, Aristipo y los cínicos. ${ }^{49}$ Kant y Fichte, es decir la tradición

46 Otto Braun ha hecho preceder su edición de los Grundlinien, en su Auswahl in vier Bänden de las obras de Schleiermacher (Schleiermacher 1910), de un índice muy útil que permite ubicarse. El aparato de la edición crítica (Schleiermacher 2002) en gran medida facilita de aquí en adelante la lectura.

47 Vorsmann (1968: 28), identifica el estilo que Schleiermacher, en el Apéndice de los Grundlinien, califica de "heurístico" y que caracteriza el estilo filosófico de Platón, con el que el mismo Schleiermacher aplicará en los Grundlinien.

48 Grundlinien, pp. 6 s. Como lo mencioné más arriba, el concepto de Selbsttätigkeit (actividad propia) se encuentra en el corazón de la explicación que Schleiermacher ofrece de la organización en serie de los diálogos de Platón, en su Introducción general a la traducción de los diálogos.

49 Los nombres de Montaigne, Hume o Helvecio aparecen también ocasionalmente (una vez cada uno). Véase el índice de nombres propios de la edición de Braun 1910: 533 s. 
de las éticas limitativas, son los más atacados (los que se asocian con mayor frecuencia, entre los antiguos, a los estoicos); en todo caso, las doctrinas de Aristóteles, de los "ingleses" y de los "franceses", 50 son también recusadas con regularidad. Pero esto no excluye algunos elogios ocasionales. Un ejemplo sorprendente, dado que es paradójico, es el tratamiento de la doctrina de Aristipo, representante de una ética de la felicidad, si es que en él la hay, y de una felicidad eminentemente pasiva (el fin es el placer, "un leve movimiento conducente a una sensación"). ${ }^{51}$ Aunque dicha doctrina evidentemente se separe del punto de vista de la doctrina de los bienes, es alabada desde la perspectiva de la doctrina de la virtud. Esto quiere decir que Aristipo, al concebir la virtud como una disposición interior, supone una concepción activa (formadora) de la ética - una concepción que a todo lector de Horacio o de Diógenes Laercio debe resultarle familiar - ${ }^{52}$ Queda por decir que el elogio es parcial y puntual. Un caso totalmente diferente es el de Platón, cuyo nombre, regularmente asociado al de Spinoza, se ve provisto de un brillo singular en los Grundlinien.53

El "divino Platón" y el "santo Spinoza" estaban ya emparentados en los Discursos sobre la religión de 1799, y Spinoza, de manera significativa, con la enseñanza de la "mística". ${ }^{54}$ La asociación de

Entre los nombres citados una vez figuran Anaxágoras, Aristón de Quíos, Heráclito y Teofrasto. Los cínicos figuran en el índice temático.

50 Se trata de Helvecio.

51 Cf. Diógenes Laercio, II, 85.

52 Horacio, Ep. I, 1, 19 s.: "Ahora recurro secretamente a los preceptos de Aristipo/ y a mi intento de someter las cosas antes que ellas me sometan"; Diógenes Laercio, II, 75 : "Poseo a Laida, pero no ella a mí; pues gobernar los placeres y no ser subyugado por ellos es lo mejor, mas no el dejar de aprovecharlos".

53 Formalmente, el estatus de excepción de la pareja Platón/Spinoza resulta del hecho de que con frecuencia son introducidos juntos, al término de un desarrollo crítico, con la fórmula "sólo Platón y Spinoza...", o bien con otras expresiones equivalentes. Cf. "Una vez más" (p. 160, asociando con ocasión de la mención de Aristipo, a Platón y Spinoza en torno al concepto de virtud).

54 Cf. Über Religion. Reden an die Gebildeten unter ihren Verachtern,p. 213 ("der heilige verstoßene Spinoza”) y p. 262 (“der göttliche Plato"). La valorización de Spinoza se inscribe en la misma línea que su defensa por parte de Herder durante la querella del "espinosismo". Spinoza había sido acusado de ateísmo por Jacobi (cf. Herder, Gott, 1787). 
los dos nombres requiere una explicación. La superioridad de los dos filósofos viene del anclaje de sus éticas en un fundamento llamado Dios o el Infinito, y de manera general de su concepción de la filosofía. Schleiermacher sostiene que en los antiguos, la división de la filosofía en lógica, física y ética opera en ausencia de un "enlace sistemático de todos los conocimientos humanos, ${ }^{55}$ y no se acompaña generalmente ni de la indicación de "un núcleo común a partir del cual estas tres ramas hayan brotado" ni de la formulación de "principios incluso superiores". ${ }^{56}$ En contraste, Platón, al elevarse hasta el punto de vista del Infinito, proporciona el fundamento de un sistema para todas las ciencias. Y al hacerlo, anticipa la Doctrina de la ciencia (Wissenschaftlehre) verdadera, de la cual Fichte inventó el nombre pero cuyo proyecto no llevó a su término. ${ }^{57}$ Ocurre lo mismo del lado de los modernos con Spinoza quien, de una manera más evidente que Platón (al menos desde un punto de vista formal), parte del Infinito. ${ }^{58}$

Sin lugar a dudas, la pareja Spinoza/Platón está movilizada contra Kant (e indirectamente contra Fichte) en la medida en que los primeros parten del Infinito mientras que Kant intenta en vano alcanzar el Infinito a partir de lo finito. ${ }^{59}$ Como lo dice Schleiermacher, la arquitectura kantiana de la razón se limita a "una división de lo dado que puede, a lo sumo, satisfacer una necesidad dialéctica" ${ }^{60}$ Sin embargo, es de notar que a Platón, tanto en este punto como en otros, se le otorga un lugar inclusive más alto que el ocupado por Spinoza. Este hecho se muestra claramente en el siguiente pasaje de la Introducción a los Grundlinien, en el que el carácter sintético proporciona una guía para la lectura schleiermacheriana de Platón (subrayo las expresiones más importantes a este respecto):

Por lo que le concierne [Platón], cualquiera que lo conozca al menos un poco debe saber cómo de repente partió del presentimiento de que

\footnotetext{
Grundlinien, p. 22.

Grundlinien, p. 21.

Grundlinien, pp. 34-38.

El primer libro de la Ética trata sobre Dios definido como la sustancia infinita.

Aunque Fichte parte del Yo infinito, parece asociado a Kant por la finitud del punto de partida (cf. Grundlinien, p. 37).

60 Grundlinien, pp. 22 s.
} 
le convenía buscar un fundamento común para la ciencia de la verdad y del bien, para la física y la ética, y cómo, al aproximarse así de cerca a los orígenes de éstas a medida que pasaba el tiempo, continuó su búsqueda de manera continua. ${ }^{61}$ Se puede también decir que, para todas las exposiciones suyas que son de importancia, ${ }^{62}$ este esfuerzo es el lugar a partir del cual la luz se esparce sobre el conjunto. El ser infinito no se le muestra solamente como siendo y produciendo (seiend und hervorbringend) sino también como poeta-creador (dichtend), y el mundo como un producto del arte de la divinidad (ein Kunstwerk der Gottheit) en devenir, compuesto de infinidad de obras de arte. Es por esto también que, dado que toda realidad particular y efectiva solamente está en devenir, mientras que solamente el formador infinito (das unendliche Bildende) es, los conceptos generales no son para él [esto es Platón], como lo son para el otro [esto es Spinoza], simple apariencia y delirio de los hombres. Sin embargo, en virtud del procedimiento contrario, son para él los pensamientos vivos de la divinidad que deben ser representados en las cosas, los ideales eternos, en los cuales y hacia los cuales todo converge. Ahora bien, como él establece para todas las cosas finitas un comienzo de su devenir y un desarrollo en el tiempo, de ahí surge también la exigencia, en todo aquello a lo que le ha sido dado una afinidad con el ser más alto, de aproximarse al ideal que éste constituye, exigencia cuya expresión más completa es la de devenir similar a Dios. Que se encuentra tanto aquí [en Platón] un vínculo muy estrecho con la ética como allá [en Spinoza] es, por tanto, manifiesto. ${ }^{63}$

La ética espinosista comporta, en efecto, una serie de deficiencias. Por ejemplo, no le otorga ningún lugar específico al ser humano, sino que vale "para todas las cosas particulares a las que puede atribuirse un alma". En consecuencia, no deja ningún lugar a una "formación" (Bildung) que suponga un camino que conduzca de lo imperfecto a lo perfecto (der Weg zur Bildung aus dem Unvollkommenen in das Vollkommene). Por esto, en razón de su desconfianza frente a los conceptos generales y de su "odio" hacia los conceptos teológicos (que Schleiermacher encuentra, además, en parte justificados: "nicht ungerechterweise”), Spinoza no tiene a su disposición un concepto

${ }^{61}$ Aquí se reconoce claramente la dualidad puesta en marcha en la Introducción: los diálogos fueron dispuestos en una serie que, simultáneamente, es a la vez "pedagógica" y también refleja el desarrollo del pensamiento.

${ }^{62}$ La formulación supone la distinción entre la obra propiamente dicha y los "diálogos de circunstancia".

${ }^{63}$ Grundlinien, p. 37. 
decisivo, a saber el de arte, Kunst ("entblösst von jeder Vorstellung einer Kunst oder eines Kunstwerkes"). ${ }^{64}$ Aunque tanto el sistema de Spinoza, como el de Platón, muestran "la manera en que el elemento ético se presenta como dotado de una actividad independiente" (esto es lo que hace, en principio, a las éticas de Platón y Spinoza sistemas de acción y de formación), ${ }^{65}$ la autonomía del ámbito moral requiere demostración en Spinoza, mientras que en Platón ella "aparece luminosamente por sí misma a través de la fórmula... de la asimilación con Dios": 66

Y es que como la divinidad está desprovista de todo aquello que se pueda llamar pulsión natural y la actividad de la potencia superior del espíritu en ella es un elemento que surge, crea e informa puramente a partir de él mismo, es manifiesto que no se podría encontrar ningún término común de comparación, si la razón en el hombre no se aplicara sino a limitar esa pulsión natural y no hiciera más que proporcionar una forma, según sus propias modalidades, a aquello que habría de producir previamente. Por el contrario, en nosotros también, no sería posible que lo esencial de la facultad superior fuera la relación con la facultad inferior, sino que solamente es la manifestación de su actividad ininterrumpida. ${ }^{67}$

De ahí que Platón sea todo lo que no es Spinoza, dado que el hombre es precisamente para él aquel animal particular que, por medio del arte, tiene como determinación esencial "formar" lo perfecto a partir de lo imperfecto asemejándose a Dios, es decir, imitando la divinidad demiúrgica con su imitación de las Ideas (i.e. los conceptos generales). La superioridad de Platón, tratándose de determinaciones sustanciales de la ética, es a lo sumo mitigada en los Grundlinien por el hecho de que su ética no presenta las virtudes formales

${ }^{64}$ Estos tres puntos figuran en la p. 36 de los Grundlinien.

65 Grundlinien, p. 58.

66 La alusión es, naturalmente, a la fórmula del Teeteto, 176 b 1.

67 Grundlinien, p. 59. El argumento desemboca en una rehabilitación de Aristóteles (Dios como pura energeia ininterrumpida), donde la posición no debería ser contada entre el número de las éticas de la limitación, por la sola razón de que él define la virtud como una "inclinación mesurada" (limitación de una pulsión natural). La cuestión de la relación entre la facultad superior y la facultad inferior jugará un papel en la crítica que hace Schleiermacher a la República de Platón, que se encuentra en la introducción a dicho diálogo, véase infra. 
que tiene la Ética de Spinoza. Esta última es, en efecto, la única que literalmente comienza por Dios, lo cual no es el caso en Platón. Es verdad que se podría, con razón, sostener que las Leyes, que son ciertamente el más teológico de los diálogos de Platón, en efecto comienzan con Dios incluso literalmente ("dios" es, de hecho, la primera palabra del diálogo). ${ }^{68}$ Pero, por razones que valdría la pena investigar, Schleiermacher nunca se interesó por este texto, considerado por él como parte de las obras anexas. ${ }^{69}$

El hecho de que Dios no constituya, por así decirlo, el primer libro de la ética de Platón es una de las razones por las cuales Schleiermacher, en el pasaje antes citado, no le atribuye a Platón más que un simple presentimiento. No se puede menospreciar la importancia de este último término. Con ello, Schleiermacher se refiere, en efecto, $a$ la vez al análisis de la forma de exposición progresiva de la filosofía platónica, la que él ha desarrollado en su Introducción general a la obra de Platón, y al hecho de que la filosofía platónica, considerada desde una perspectiva doctrinal y sistemática, a pesar de sus méritos permanece fundamentalmente incompleta - una idea que, por importante que sea, no proviene ni puede provenir de la Introducción, en la medida en que, como hemos visto, deja deliberadamente de lado las cuestiones relativas al contenido doctrinal- - Si la ética de Platón es incompleta, no es en el sentido de que no trate todos los puntos que una ética debe cubrir, dado que por el contrario, éste es uno de los grandes méritos de la ética platónica: el hecho de ser completa en ese sentido. Pero es incompleta porque, por una parte, en virtud de la forma misma de la obra platónica, los diferentes aspectos no están allí desarrollados ni sistemáticamente articulados y, por otra parte, porque según él, Platón se equivoca e incluso cae en la inmoralidad. Sobre este tipo de figura los Grundlinien no dicen nada - hay allí un rasgo sobresaliente del que Schleiermacher estaba perfectamente consciente.$-{ }^{70}$ Pero la introducción de Schleiermacher a la Repú-

68 El primer libro de las Leyes presenta la ley como otorgada por el dios.

${ }_{69}$ Véase la Introducción general, p. 51.

70 Véase la carta del 30 de julio de 1803 a Henriette Herz: "Pero he mantenido bastante esotérico el reproche en contra de Spinoza y de Platón, de manera que quien no tenga buenos ojos no lo verá" ("Nur den Tadel gegen Spinoza und Platon habe 
blica no es ambigua en este punto, lo cual es todavía más impactante si se toma en cuenta el hecho de que la República no es para Schleiermacher una obra más, sino que constituye, como lo hemos visto, el único diálogo donde la ética platónica está propiamente expuesta - todos los demás diálogos relativos a la ética no tendrían, a lo sumo, más que un valor preparatorio o propedéutico.$-{ }^{71}$ Esto no significa que Schleiermacher, en esta introducción, no le reconozca a la República un cierto número de méritos, y hasta los más altos. La maestría en la construcción del conjunto es calificada como "suntuosa" y los desarrollos concernientes a la Idea del Bien son alabados desde una perspectiva que hace eco (aunque se trate de un eco un poco débil) a las declaraciones frecuentemente entusiastas de los Grundlinien. ${ }^{72}$ Pero la crítica es feroz. Por una parte, se concentra en el paralelismo entre el alma y el Estado que, según Schleiermacher, es fatal tanto para la concepción platónica del alma y de sus virtudes como para las disposiciones particulares que se siguen de esta concepción, y que él mismo denuncia en términos fuertes y marcados (la doctrina es "sacrílega", las instituciones platónicas son fuente de "repulsión"). ${ }^{73}$ No entraré en detalles. Para quien conozca un poco la República no será difícil ver cuáles son los puntos que provocan la indignación de Schleiermacher: las disposiciones comunitarias, claramente las relativas al matrimonio y al amor; entre la clase de los guerreros y de los magistrados, el recurso a la mentira política; en resumen, un conjunto de tratamientos característicos de la ciudad platónica evidentemente incompatibles con los principios cristianos y liberales, por lo menos, y hasta los democráticos..$^{74}$ De suerte que, a pesar de la continuidad indiscutible que existe entre los Grundlinien y la introducción a la República (concerniente de manera nota-

ich recht esoterisch gehalten, und wer nicht gute Augen hat, wird ihn nicht sehen"), Aus Schleiermachers Leben. In Briefen, 1, 1860, p. 373.

71 Cf. supra, p. 43. Schleiermacher considera que, a pesar de las justificaciones que se pueden encontrar, la República está mal nombrada: su título no corresponde con lo que es el contenido propio y el Estado no constituye sino un tema secundario.

72 El pasaje relativo a la Idea del Bien en la introducción a la República figura en las pp. $40 \mathrm{~s}$.

73 Introducción, p. 33.

74 Las críticas de Schleiermacher fueron analizadas por Zimbrich 1990. 
ble a la doctrina del Bien supremo), lo que sorprende es, más bien, la distancia que separa el tratamiento que se hace de Platón en los Grundlinien, que es exclusivamente positivo, del tratamiento de la introducción, donde domina la crítica.

¿Se trata, entonces, de una evolución entre los Grundlinien de 1804 y la introducción a la República de $1828 ?^{75}$ Aunque ciertos desarrollos de la introducción están indiscutiblemente marcados por preocupaciones contemporáneas y son, en un sentido schleiermacheriano, "de circunstancia" (éste es particularmente el caso de las reflexiones sobre la necesidad que tiene un Estado de poseer o no un ejército profesional),${ }^{76}$ esta hipótesis puede ser descartada. Esto supondría que en 1804 Schleiermacher sencillamente no había leído la República o, entonces, que su concepción tanto del amor y el matrimonio, como del Estado en general e incluso de la guerra, habían cambiado de manera fundamental, lo que, dada la naturaleza de los temas en cuestión, parece poco verosímil. Ello, además, es refutado por la carta de Schleiermacher a Henriette citada más arriba. ${ }^{77}$

En un artículo publicado en 1992, E. Herms sostuvo que, en materia de ética por lo menos, Schleiermacher no es platónico, sino antiplatónico - antiplatónico no solamente por ser cristiano (y, falta decir, "liberal"), sino también porque sería, en materia de ética, aristotélico- . No voy a abordar aquí la cuestión del aristotelismo de Schleiermacher. En cuanto a su platonismo, éste será objeto de un trabajo independiente. Sólo quiero sugerir que la manera

75 Como se ha visto (cf. supra, n. 36), se pueden señalar ciertos cambios en la interpretación que Schleiermacher hace de Platón.

76 En sus comentarios a la traducción de $374 \mathrm{e}$, Schleiermacher se toma el tiempo de anotar: "tan es así que no se puede ser principalmente un hombre de guerra, siendo al mismo tiempo zapatero de manera accesoria, dado que esta profesión debe ser practicada con arte; por el contrario, se puede ser esencialmente zapatero o cualquier cosa del mismo género, y entrenarse de manera paralela y suficiente para una guerra eventual" (Platons Werke, III/l, Berlin, $1862^{2}$, p. 344). Como lo subraya Zimbrich 1990:191, "la institución platónica se opone de manera tan tajante a la restructuración que conoce el ejército prusiano en el marco de las grandes reformas (el servicio militar obligatorio, hacia el cual había una tendencia desde 1809, fue adoptado en 1814), que Schleiermacher, quien defiende esta evolución política, no puede sino oponerse de manera categórica a Platón".

77 Véase supra, n. 70. 
en la que Herms da cuenta del extraordinario elogio de Platón en los Grundlinien - elogio evidentemente paradójico, si la ética de Schleiermacher es de orientación aristotélica y las críticas de 1828 están, por consiguiente, ya virtualmente presentes en $1804-{ }^{78}$ no es ni la única posible, ni la más verosímil. La idea de Herms es que los Grundlinien no se interesan sino en la forma de las éticas anteriores,${ }^{79}$ lo que implicaría su neutralidad en cuanto al contenido de las tesis efectivamente defendidas. Herms puede así establecer un contraste entre "la aprobación sin reserva que hace Schleiermacher de la forma de la ética científica" (en Platón), la "crítica decidida de las determinaciones de la ética en Platón desde el punto de vista de su contenido", y la que Schleiermacher presenta en la introducción a la República.$^{80}$ Herms parece apelar a una declaración expresa de Schleiermacher en el Prefacio de los Grundlinien: "Es gibt nämlich gar für jede eigentliche Wissenschaft, wie doch die Ethik sein will und soll, keine andere Kritik, als die der wissenschaftlichen Form, und eine solche aufzustellen soll hier versucht werden" ("No hay de hecho, en efecto, para cada ciencia auténtica, como la ética es y debe ser, ninguna otra crítica distinta que aquella de la forma científica - y es esa clase de 'crítica' que se debe intentar establecer aquí-"). ${ }^{81}$ Sin embargo, me parece que no se puede oponer así la forma al contenido, cuando menos por dos razones: en primer lugar, porque Schleiermacher dice de manera absolutamente explícita que la forma y el contenido se determinan recíprocamente; ${ }^{82}$ en segundo lugar, porque de hecho, las determinaciones que se llaman formales son, en efecto, determinaciones sustanciales. Esto vale como principio fundamental de la ética así como de los conceptos éticos - por

78 Recordemos que Aristóteles es el primero en criticar las disposiciones más cuestionables de la ciudad platónica en el libro II de su Política.

79 Aquí se trata, evidentemente, de la forma en el sentido de la estructuración interna de los sistemas y de sus componentes, y no de la forma de exposición que, en el caso de Platón, es el objeto de la Introducción de 1804 y es igualmente abordado por Schleiermacher en los Grundlinien en el marco de un Apéndice especialmente consagrado a la pregunta por el "estilo de las doctrinas éticas".

80 Herms 1992: 6.

81 Herms 1992: 9.

82 Grundlinien, p. 10. 
ejemplo y en particular cuando Schleiermacher exige que la virtud sea "formadora".

Me parece que el par pertinente para comprender la relación del elogio con la crítica no es el de la forma y el contenido, sino el del presentimiento (cuya importancia señalé arriba) y la realización. Si el primero es bueno, siempre es posible que la segunda sea deficiente, de suerte que el elogio se dirigirá al presentimiento y la crítica a la realización. Esta hipótesis recibe una confirmación al menos indirecta en el hecho, no mencionado en ninguna parte, si no me equivoco, de que la reconstrucción de la ética platónica que se presenta en los Grundlinien se genera a partir de elementos que no son específicos de la exposición oficial de la ética platónica, a saber la República, sino que provienen esencialmente, como lo vimos, del Timeo (es decir, la exposición oficial de la física). Quizás hasta se podría decir que, para Schleiermacher, Platón en materia de ética es platónico a pesar de él mismo.

\section{Bibliografía}

Fuentes

\section{SCHLEIERMACHER}

Sämtliche Werke, Berlin, 1834-1864 (1. Abt.: Zur Theologie, 11 vols.; 2. Abt.: Predigten, 10 vols.; 3 Abt.: Zur Philosophie, 10 vols.).

Grundlinien einer Kritik der bisherigen Sittenlehre

- en Werke. Auswahl in vier Bänden, ed. Otto Braun. Leipzig, 1910.

- en Kritische Gesamtausgabe, vol. 5 (Schriften aus der Stolper Zeit, 1802-1804) ed. Eilert Herms y Michael Pietsch. Berlin-New York, W. de Gruyter, 2002.

Über Religion. Reden an die Gebildeten unter ihren Verachtern, en Kritische Gesamtausgabe, vol. 6, 1984: 185-326.

Platons Werke, 5 vols. en 2 partes, Berlin 1804-1810; $2^{\text {a }}$ ed., 6 vols. en 3 partes (con la República, la $^{\mathrm{a}}$ ed.) Berlin 1816-1828; 3ª ed. (República, $2^{\text {a }}$.ed.), Berlin, 1855-1862.

"Über den Werth des Sokrates als Philosophen", Abhandlungen der königlichen-preussischen Akademie der Wissenschaften, 1814-15, pp. 50-68 (=Sämtliche Werke 3. Abt., Bd. 2: 287-308). 
Geschichte der Philosophie, ed. Hans Ritter, 1839 (Sämtliche Werke 3. Abt. Bd. 4, 1 = Über die Philosophie Platons, ed. Peter M. Steiner, Hamburg, 1996: 3-20).

Aus Schleiermachers Leben. In Briefen, ed. Ludwig Jonas y Wilhelm Dilthey. Berlin, 1860.

OTROS AUTORES

HERDER, Johann Gottfried, Gott. Einige Gespräche über Spinoza’s System. Gotha, 1787.

SchlEGEL, F., Kritische-Schlegel-Ausgabe $(=K A)$, Ernst Behler, Jean-Jacques Anstett, Hans Eichner (eds.), vol. XI, 1958.

Tennemann, Wilhelm Gottlieb, System der Platonischen Philosophie, 4 vols. Leipzig, 1792/1795.

Estudios

ARndT, Andreas (1996). "Schleiermacher und Platon", en Schleiermacher, Über die Philosophie Platons (Peter M. Steiner, ed.). Hamburg, Felix Meiner Verlag : VII-XXII.

- (2002). “Das Unsterbliche mit dem Sterblichen verbinden'. F. Schleiermacher und Platons Symposium", en S. Matuschek (ed.), Wo das philosophische Gespräch ganz in Dichtung übergeht. Platons Symposium und seine Wirkung in der Renaissance, Romantik und Moderne. Heidelberg, Winter : 163-173.

Asmuth, Christian (2006). Interpretation - Transformation. Das Platonbild bei Fichte, Schelling, Hegel, Schleiermacher und Schopenhauer und das Legitimationsproblem der Philosophiegeschichte. Göttingen, Vandenhoeck \& Ruprecht.

BRINO, Omar (2007a). L'architettonica della morale, Schleiermacher tra architettonica della morale e scienza della storia. Trento, Editrice Università degli Studi di Trento.

- (2007b). "Dikaion kai hosion. Platone nelle Grundlinien di Schleiermacher", en Domenico Venturelli et alii (eds.), Etica, religione e storia. Genova, Il nuovo Melangolo: 415-441.

Brisson, Luc (ed.) (1998). L'interprétation ésotériste de Platon = Etudes Philosophiques, Janvier-Mars 1998.

Dilthey, W. (1966/1970). Leben Schleiermachers (1870) en W. Dilthey, Gesammelte Schriften, vol. XIII y XIV (M. Redeker, ed.). Göttingen, Vandenhoeck \& Ruprecht.

GADAMER, Hans-Georg (1979). "Schleiermacher als Platoniker”, en HansGeorg Gadamer, Kleine Schriften, vol. III. Tübingen. J.C.B. Mohr (P. Siebeck): 141-149.

Herms, Eilert (1992). "Platonismus und Aristotelismus in Schleiermachers Ethik", en Sergio Sorrentino (ed.), Schleiermacher's philosophy and the philosophical tradition. Lewiston, N.Y., E. Mellen Press: 3-26. 
LaKs, André (1990, 2008²). "Platonisme et système chez Schleiermacher des Grundlinien à la Dialectique ", en André Laks y Ada Neschke (eds.), La naissance du paradigme herméneutique. Villeneuve d'Ascq, Presses Universitaires du Septentrion: 155-181.

- (2011). "L’Héraclite physicien de Schleiermacher", en Oliver Primavesi y Katharina Luchner (eds.), The presocratics from the Latin Middle Ages to Hermann Diels : Akten der 9. Tagung der Karl Und Gertrud Abel-Stiftung vom 5.-7. Oktober 2006 in München. Stuttgart, F. Steiner: 281-309.

- y Ada Neschke (eds.) $\left(1990,2008^{2}\right)$. La naissance du paradigme herméneutique. Villeneuve d'Ascq, Presses Universitaires du Septentrion.

Moretto, Giovanni (1984). "Platonismo e romanticismo. Platone nei 'discorsi sulla religione' di Schleiermacher", Archivio di filosofia, vol. 52: 233-269.

NeschKe-HentschKe, Ada $\left(1990,2008^{2}\right)$. " Platonisme et tournant herméneutique au début du XIxe siècle en Allemagne”, en André Laks y Ada Neschke (eds.), La naissance du paradigme herméneutique, Villeneuve d'Ascq, Presses Universitaires du Septentrion (1990, 2008²): 109-132.

RoHLs, Jan (2000). “ 'Der Winckelmann der griechischen Philosophie'. Schleiermachers Platonismus im Kontext", en Ulrich Barth (ed.), 200 Jahre 'Reden über Religion'. Akten des 1. Internationalen Kongresses der Schleiermacher-Gesellschaft. Berlin-New York, Walter de Gruyter: 467-496.

Szlezák, Alexander T. (1985). Platon und die Schriftlichkeit der Philosophie. Interpretationen zu den frühen und mittleren Dialogen. BerlinNew York, Walter de Gruyter.

- (1997). "Schleiermachers Einleitung zur Platon's Übersetzung von 1804. Ein Vergleich mit seinen Vorgängern Tiedemann und Tenemann", Antike und Abendland, vol. 43: 46-62.

Scholtz, Günther (1984). Die Philosophie Schleiermachers. Darmstadt, Wissenschaftliche Buchgesellschaft.

- (1995a). Ethik und Hermeneutik, Schleiermachers Grundlegung der Geisteswissenschaften. Frankfurt am Main, Suhrkamp.

- (1995b). "Schleiermacher und die platonische Ideenlehre", en K.-V. Selge (ed.), Internationaler Schleiermacher-Kongress (1994). Berlin-New York, Walter de Gruyter: 849-871.

ThOUARD, Denis (1998). "Tradition directe et tradition indirecte. Remarque sur l'interprétation de Platon par Schleiermacher et ses utilisations", Etudes Philosophiques: 543-556.

Vieillard-Baron, Jean-Louis (1979). Platon et l'idéalisme allemand (1770-1830). Paris, Beauchesne.

Vorsmann, Norbert (1968). Die Bedeutung des Platonismus für den Aufbau der Erziehungstheorie bei Schleiermacher und Herbart, Ratingen b. Düsseldorf, Henn. 
Zimbrich, Ulrike (1990, 2008²). “ 'Un Etat étrangement imaginé'. La République de Platon d'après Schleiermacher", en André Laks y Ada Neschke (eds.), La naissance du paradigme herméneutique. Villeneuve d'Ascq, Presses Universitaires du Septentrion: 183-196. 
